lysed, and there was an aneurism of the right internal carntid pressing on the lower or front part of the crus cerebri.

As regards paralysia of one side of the face and of one or two lower limbs, very few cases are on record. Not one of them is in harmony with the admitted views concerning the origin of paralysis. I will only mention two such cases which 1 have already spoken of for other purposes. In a case of tumour in the left corpus striatum, Lind ${ }^{23}$ noticed paraplegia and facial paralysis. In a case of softening of the white substance of a part of the middle and posterior lobes on the left side, Albers ${ }^{24}$ noticed a paralysis of the lelt side of the face and of the right lower limb.

\section{ON LTTHOTOMY BY THE RECTANGULAR STAFF.}

BY GEORGE H. B. MACLEOD, F.R.S.E.,

REGIUS PROFESSOR OF SURGERY, UNIVERSITY OF GLASGOW ; AND LECTURER ON CLINICAL SURGERY, WESTERN INYIRMARY.

Is the year 1848, there was published in the Edinburgh Monthly Journal a paper on " Lithotomy performed with the Rectangulir Staff," by my venerable and esteemed friend, the Emeritus Professor of Physiology, Dr. Andrew Buchanan, in which he first described the staff which observation and experiment had caused him to adopt as the most efficient guide to the bladder. The method of operation there set forth, while it has become the prevailing one in this school, gaining more and more the confidence of those who have followed it, has not, $I$ think, attracted the attention elsewhere which its great merits deserve. It is now a consider. able number of years since Dr. Buchanan ceased to be connected with the hospital, but I well remember the in terest which was unfailingly evinced when " an operation for stone" was announced by the then "new method." Since 1848 very little change has been made in the steps of the procedure referred to, and if in the sequel I venture to propose a certain modification in the staff it is because I believe it enables us to overcome the few objections which can be made to the operation as ordinarily performed. I would desire also in this paper to draw attention to various details in the operation with the rectangular staff which are not usually understood, and which are essential to its successful performance. I may at once say that in Glasgow the rectangular staff is almost exclusively employed, and that confidence in it has steadily increased from year to year, while I do not think it has ever been fairly tried elsewhere, unless I except its occasional use by Mr. Hutchinson in London. I cannot but hope that if its merits were better known it would be adopted by the profession in general throughout the country.

In the original paper the author tells us how he was led by a perusal of Dupuytren's "Memoir on Lithotomp" to institute experiments, and how gradually he came to fashion his new staff, and adopt the "improved method of penetrating into the bladder, and dividing the more external parts." The staff used by Dr. Buchanan is bent at right angles three inches from the point, and is hence

FIG. 1.

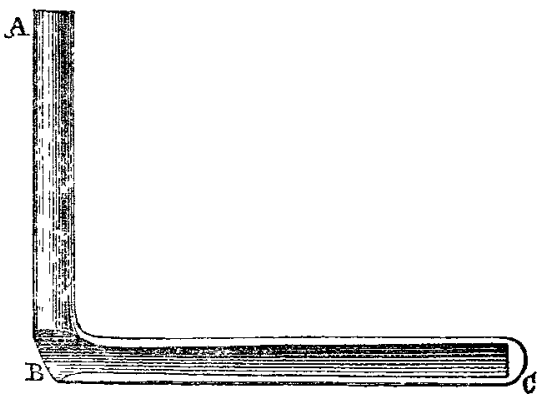

"rectangular." It has a lateral groove along the borizontal part (B, C, Fig. 1), and the end of this groove is closed at $\mathrm{C}$.

23 Quoted by Ladame, loc. cit. No. clviii., p. 174

24 Annales irédico-Psychologiques (1861), vol, vii., p. 615
When the instrument is introduced, the argle $B$ lies in the membranous part of the uretbra, close in front of the prostate gland, and can be felt by the finger placed in the rectum, or by a little pressure on the perinenw, to occupy a point a little in front of the anus. The borizon'al part lies parallel to the rectum, and extends in to the bladder.

In operating, the staff is so held as to occupy an intermediate position between being hooked up under the pubis and being pressed down on the perineum, ${ }^{1}$ and the operator keeps it steady and distinguishes its correct position by placing his left forefinger in the rectum under its horizontal part. The thumb of the left hand is at the same time pressed gently in front of the anus, so as to mark the site of the angle and to keep it steady. The exact position of the angle is very easily determined, as there are only the skin, superficial fascia, and some fibres of the sphincter between it and the thumb. The knife used is a straightbacked one, whose blade exceeds in length the grooved portion of the staff by about one-fourth of an inch. The point is sharp, and it should have a cutting edge on its back for about half its length, by which the tissues along the groove are more surely divided towards the middle line of the perineum. The shoulder of the knife is low, and the breadth of the blade equal from shoulder to hilt.

When the patient has been tied in the usual position, and the staff placed as above described and fixed by the operator's lett hand, the knife (held short and above the hand, palm upwards) is slowly inserted close above the anus, "just where the mucous membrane shades into skin," and close to the rapbé. The edge is turned to the left side of the perinenm, or to the operator's right. The blade is not introduced parallel to the horizontal part of the staff (which would greatly increase the risk of its escaping from the groove as it passed on into the bladder), but obliquely, so as to impinge on the groove at an angle; and as it is afterwards pushed on towards the bladder, a slight obliquity is still maintained, so as to assure the operator that the point is in the groove, and to ensure its non-escape therefrom. In this way the whole length of the groove is traversed, and the point of the blade finally arrested by the closed end of the staff. It is then best slightly to withdraw the blade and to complete the division of the soft parts as it is brought out, the knife being "lateralised" and made to cut in a semicircular direction between the anus and the tuberosity to a point rather behind the level of the anus. This whole cut may measure from $1 \frac{1}{3}$ in. to $1 \frac{1}{2}$ in. according to the development of the parts. "It approaches," says Dr. Bucbanan, "very nearly to one-half of Dupuytren's incision, only it lies much nearer the rectum, and, though little different in size, involves a larger portion of the circumference of the intestine." Nothing now remains but to insert the left forefinger, following the borizontal portion of the staff into the bladder, and dilate the very limited wound found in the prostate, while the staff is withdrawn and the stone extracted in the usual way.

It will be observed that no incision is made over the angle of the staff before it is penetrated. To make such a preliminary cut only complicates matters. No aid is got from it, and the parallelism of the two cuts is difficult to ensure. The staff is opened at one thrust, and if the precautions above described are taken there is no danger in this step. The knife should never be pushed on till the operator feels confident that it is in the groove. This the grating of the point of the knife on the groove makes very evident to him, and the assistant holding the staff also plainly perceives it.

From the above description it will be apparent-(1) That in this method of operating, only one incision $n \mathrm{r}$ cnt is, as a rule, required, and no dissection called for. (2) 'That the incision lies lower down (i. e., nearer the anus) than in Cbeselden's operation. (3) That the urethra is opened considerably nearer the bladder than it is in the lateral nperation. (4) That a straight, short, and direct road is followed to the bladder; the prostate gland being reached at once at the point where it m. at nearly approaches the surface of the perineum. (5) That less injury is done to the sof parts

1 At first the heel was pressed down on the perineum so as to raise the tissues, as it were, over it, and make its position verv prominent. The late A1r. Watt used to place the horizontal part of the s'aff so that the heel lay rather to the righ of the raphe and the point inclined to the left (within the prostate), hy which the grooved portion lay more directly in the course of the knife as it entered, and the staff was at the same time, he thought, more firmly fixed. 
of the perineum and the urethra than in the ordinary operation, the incision, though all that is necessary for the purpose in view, being much shorter and more limited (6) That there is much less danger of wounding important bloodvessels, as the incision does not go near them. (7) That the rectum is, by the action of the horizontal portion of the staff, rendered straight, and is therefore not in the least danger of being wounded, as at first might be supposed it would be. (8) From the near neigh hourhood of the anus to the incision the wound is easily stretched or dilated, so that it does not require to be of great size. (9) A more limited inoision is made in the neek of the bladder than is usually inflicted in the lateral operation, and the wound lies in the longest axis of the prostate. (10) If the stone is very large and much room is needed, the right side of the prostate is easily reached, and can be incised with a probepointed bistoury.

In short, I hold that this mode of operating most perfectly fulfils all the requirements of an easy, rapid, and safe access into the bladder; that the surgeon cannot go wrong who exercises the most trifling care; that there is the least injury to structures and the minimum risk of comolications; that it provides the shortest road for the stone to travel as it is extracted, and that the most direct and efficient drain for the urine is established.

In speaking to hospital surgeons elsewhere of this operation, I bave always found that their ohjections to use it were either, (1) the supposed diffinulty of introducing (especially in children) a staff of the rectangular form; (2) "the stab in the dark," as the passing of the knife into the angle was occasionally termed; (3) the risk of the knife escaping from the groove; and, lastly, the supposed danger of wounding the rectum.

There is no doubt but that the first objection is well founded. It requires care to pass the beel of the staff especially through the meatus, even though the operator catches the staff short (as he should do), and exercises every care. So, too, in watching the beel, beginners are apt to get the point caught at the subpubic curve, and it was to overcome this difficulty that I had the staff changed, as afterwards described. The second objection has not much practical force. The heel is so easily defined by the forefinger and thumb of the left hand applied in the way above indicated, that it is readily entered. Yet some operators hesitate to attempt this by one movement of the knife, and make a preliminary incision to that by which the point of the blade is placed in the groove. This should, however, be avoided, as was before explained. The third objection is groundless if the rule I gave is followed-viz., to insert the knife at an angle into the groove, and to keep it at a slight angle to the horizontal portion of the staff all the way in to the bladder. It this way the groove is "felt" all the way by the point of the knife. The fourth objection is quite untenable. It is suggested by experience of the curved staff, which, from its shape and the way it is beld in litbotomy, exaggerates the curvature of the bowel. The rectangular staff, on the contrary, renders the upper surface of the rectum straight, and no injurg whatever to the bowel attends an operation performed with it. There is a tradition in the school that it was once wounded, but I have never known it happen in my day.

It was, however, to overcome the force of the first and second objections that I was led to alter the construction of the rectangular staff. After trying various expedients, I have finally had the staff kinged by a very simple and effective mecbanism, ably executed by Mr. Hilliard, of this city (see Fig. 2), so that when being introduced it can be placed in the most favourable position for being passed along the canal, and when it is in place, by turning a screw in the handle, it is firmly fixed in a rectangular position. The pressure of the left forefinger in the rectum brings it to its right-angled position (and that it cannot pass), and then two turns of the screw fixes it there. By this simple plan much is gained. First, all difficulty of introducing it is overcome. Secondly, the heel of the staff (which is the point we seek for, and which there may be a difficulty in finding if the staff is a small one,) may be greatly enlarged (widened and made more easily detected), and so more surely entered. And, thirdly, the removal of the staff from the urethra is also facilitated, as by reversing the screw the horizontal portion is allowed to fall, and so the angular shape of the staff done away with. So long as the staff was rigid at the angle the heel had to be kept small, as it was in passing it through the meatus, and in crnducting it and the point along the canal that tbe difficulty lay, but with the hinge at the angle a large wide heel can be easily passed, and so made available.

\section{Fig. 2.}

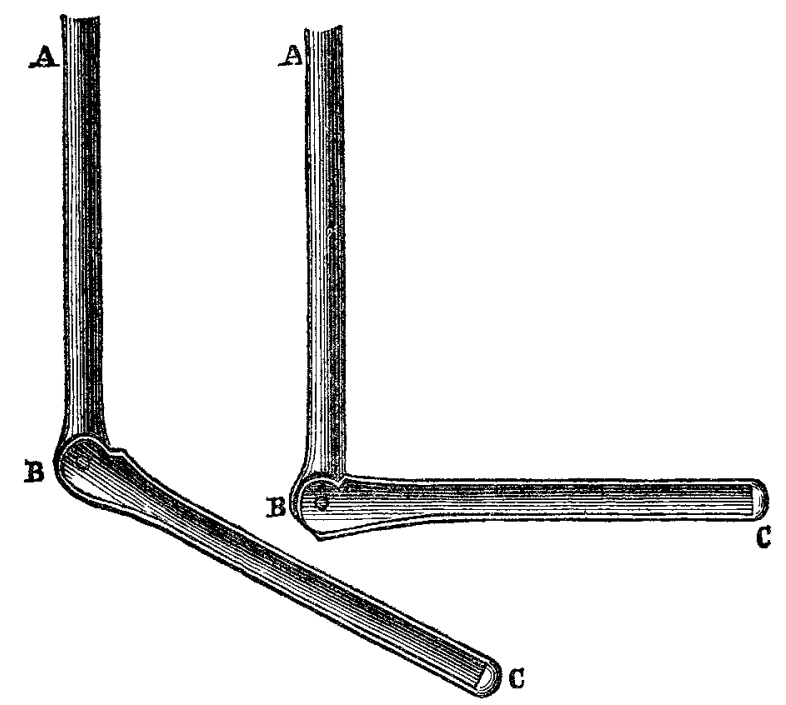

I have used this new instrument four times on the living with great satisfaction and the hearty approbation of those who have seen its simplicity of action.

In order to overcome the distrust some have of passing the knife at once into the groove, I some time ago tried a plan of inserting from the perineum, at the point where the kaife is to enter, a sharp steel director set in a handle, as shown in Fig. 3. The groove in the staff was so made Fira. 3.

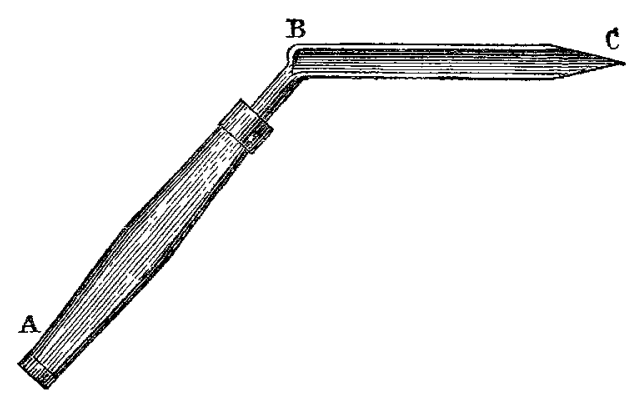

that this director fitted accurately into it, and when pushed home got fixed into the groove. The director was intro. duced just as it was before described the knife should beviz., a little obliquely to the horizontal part of the staff, and so soon as its point was felt to be in the groove it was pushed on parallel to the groove till it fixed itself in it. A tiny stream of urine came along the groove in the director, showing at once that a road to the bladder had been secured, and the knife was then run along the combined grooves of the director and staff, and the operation completed in the usual way. One advantage of this plan was the perfect firmness with which the staff was fixed and held in place by the director, and the great prominence you could give to the angle of the staff in the perineum before the director was inserted, as so soon as it was in place you could adjust the horizontal part of the staff, and fix it as you pleased. I operated several times on the dead subject in this way, and once on the living. It was quite successful, but too mechanical for common use, and, as I believe that all diff. culty of finding the heel of the staff is overcome by the device I have related in this paper, I have not pursued the practice of using the director now mentioned.

It is well known that Mr. Earle contrived an outside guide to the ordinary lithotomy staff, and the late Dr. Corbett tried a similar arrangement for the rectangular one. His instrument is depicted in Fig. 4 . Its adjustment was troublesome and not always accurate, and its application 80 purely mechanical that it never came into use; but if carefully applied, it secures the passage into the bladder in a manner so obvious and certain, that the merest novice may pursue it, so far as the mere incision from the surface is concerned. The sharp-pointed $(\mathrm{E})$ outside staff, when pushed in through the tissues of the perineum, at once fixed 
itself in the true staff (B) lodged in the uretibrd, and the knife was run along the united grooves ( $D$ to $C$ ) from the surface into the bladder.

I may further remark, in conclusion, that in this school there is a remarkably good and sure plan of catching the stone employed which I have never seen used elsewhere nor described by anyone. After the forceps bave been passed into the bladder in the usual way, and the position of the stone ascertained, if it is lying, as is usual, on the floor of the bladder (and elevating the pelvis by placing a pillow under the hips greatly facilitates the manoouvre), the handles of the forceps are widely separated by the operator taking one in each bavd, and then by a sudden sweeping movement he

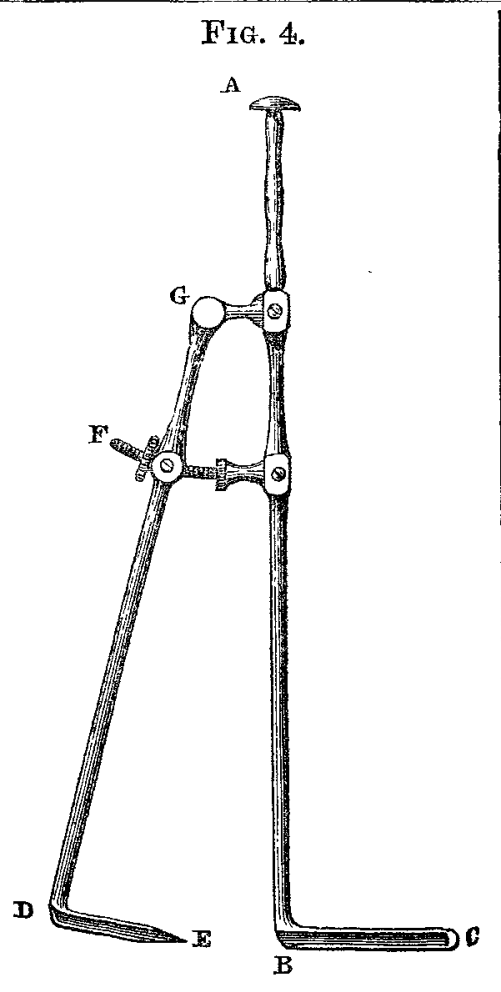

brings his right hand downwards and his left upwards, by which the right blade is with very great certainty passed under the stone, and it is finally grasped by approximating the hands. Every operator will acknowledge that laying held of the stone is of ten the most troublesome part of the operation, and this $I$ believe is in no small measure due to the forceps being $u$ sed, like scissors or sugar-tongs, with one hand, and not with both hands, as here stated.

I am nnder obligation to my friend and late house-surgeon, Dr. Moffat, for the drawings illustrating this paper.

\section{INSANITY ASSOCIATED WITH AN ABSCESS CONNECTED WITH THE EAR; CURED BY OPENING THE ABSCESS.}

By W. RHYS WILLTAMS, M.D., BREIDENT PUYSIOTAN, BETHTEM ROTAY BOSPITAL.

For the notes on this case $I$ am indebted to my colleague, Dr. Savage.

Charles D. C-C, twenty-six, married. No insane relations. Has enjoyed good health. Industrious and sober. Thirteen days before admission he became depressed, and rambling in his conversation. In a few days he became excited, noisy, violent, and incoherent. He believed he was firing rockets at Edinburgh Castle. He was continually swearing and screaming out violent language, said he saw devils, and believed that all his actions were influenced by electricity. He was noisy and sleepless at night.

On admission, February 24th, 1876, he was violent and noisy; in a few days he became quiet, but was very sullen, refusing to answer questions. A fortnight after admission he was again excited, talking to himself incoherently, and striking attitudes. General health good, but he was sallow and thin. In November we noticed that be had a profuse purulent discharge from the left ear. He said he had had this for montbs past. Hearing seemed unaffected. Slowly a large puffy swelling formed over left mastoid process, and spread up over squamous portion of temporal. On pressing this the discharge ran freely from the meatus. The swelling steadily increased for a month, but the patient was sullen and dangerous, and would not allow anyone to examive him. He had not been noisy after the first ten dasys in the hospital, but was very insane, keeping to himselt and fancying we wanted to influence or injure him. He was abusive at times.

On December 13 th the abscess was opened under ether spray, and he became sane at once. No further discbarge tonk place from the exr.

A fortnight later, under chloroform, a free incision and careful exploration were made. No cause for the discharge was found.

On January 29 th a second exploration was made because of the wounds having healed, and there being no discharge from the ear. He complained of severe frontal headache and general malaise.

Mr. Wagstaffe had operated on all these occasions, and bas kindly supplied bis notes. From this time the wounds steadily bealed, and the patient improved in every way, and after watching him hor six weeks we discharged him well.

The first opening of this abscess was simply at the most dependent point about three incbes below the mastoid process, and behind the sterno-mastoid, and owing to the patient being troublesome it was impossible to examine carefully through the incision by a probe.

The second operation, on Jan. 9th, was undertaken because the lower wound had a tendency to elose, and it was evident that the main part of the abscess was in relation to the mastoid process, and might be due to some movable sequestrum. An incision was made, under chloroform, behind and below the mastoid process, and therefore through part of the attachment of the sterno-mastoid. When this had been enlarged sufficiently to admit the finger it was found that the abscess cavity passed backwards and downwards for fully two inches under the sterno-mastoid, and inwards along the base of the skull for apparently about an inch beyond the mastoid process, while forwards it also extended arout an inch. It seemed to be limited therefore in front by the parotid, which was not affected as far as nne could jurge, and internally by the rectus lateralis, and the internal jugular vein. No bare bone could be felt in any direction, nor could any be found in front of the mastoid by a probe. It appeared as if the abscess had arisen beneath the mastoid process, but from what source was not at all clear. The discharge from the ear points to the front of this process as the original seat of disease, and it was about this region that the greatest tenderness was at first experienced. There was no deafness resulting, and the mischief was apparently external to the position of the membrana tympani.

We have had several cases recently in Bethlem Hospital, in which mental symptoms have abated on the onset of acute maladies, or painful affections, especially when these have implicated cranial nerves. We also had a woman suffering from violent puerperal mania who recovered almost instantaneously on the opening of symmetrical abscesses in the calves. In the case now reported the interest is in the seat of the disease, and its near relation to the brain. We cannot say whether there was distinct propagation of inflammation to the brain, or, what is more probable, if there was merely some conducted disease along a cranial nerve.

Bethlem Royal Hospital.

\section{THE ANHYDROUS DRESSING OF WOUNDS.}

Bx ROBERT HAMILTON, F.R.C.S., SURGEON TO THE ROYAL SOUTHERY HOSPITAL, LIVERPOOL.

Notwithstanding the very important position in the practice of surgery which the best dressing of wounds, lacerations, and abrasions of the surface of the body has assumed, still if further improvements can be suggested, and a nearer approach to perfection in aiding nature in the process can be obtained, the whole art of surgery will be benefited. For wounds, in one sense, may be called fingerposts which point the way to restoration of tissue in deeper parts; and what may be seen and observed to go on in them indicates what are the modes and processes which take place in several departures from the healthy standard that occur in parts which lie below the surface; for instance, internal abscesses of various kinds.

The improvement which has taken place of late years in the mode of treating wounds is striking. The way in which the healing processes set up in lesions of the surface, eren 